\title{
REGULATION OF EFFICACY AT CENTRAL SYNAPSES ${ }^{1}$
}

\author{
HENRI KORN,² DONALD S. FABER,* YVES BURNOD, AND ANTOINE TRILLER \\ Institut Pasteur, Institut National de la Santé et de la Recherche Médicale, Laboratoire de Neurobiologie Cellulaire, INSERM \\ U261, Département de Biologie Moléculaire, 25 Rue du Docteur Roux, 75015 Paris, France, and *Division of Neurobiology, \\ Department of Physiology, School of Medicine, State University of New York at Buffalo, Buffalo, New York 14214
}

Received May 3, 1983; Revised July 19, 1983; Accepted July 19, 1983

\begin{abstract}
The quantal nature of synaptic depression produced by high frequency stimulations has been analyzed at a central synapse for the first time. Simultaneous intracellular recordings were obtained from the Mauthner cell and adjacent identifiable inhibitory interneurons. The presynaptic cells were stimulated at frequencies from 2 to $33 \mathrm{~Hz}$, and the corresponding release parameters were determined using a computational procedure described elsewhere (Korn, H., A. Triller, A. Mallet, and D. S. Faber (1981) Science 213: 898-901). As in our previous studies, these entities were correlated with histological features of the neurons following systcmatic horseradish peroxidase injections and reconstructions. Evidence was obtained that, in the range of physiological conditions used, the binomial parameter $n$ (number of available quanta for release) remains constant; thus every synaptic bouton continues to function as an independent all-or-none releasing unit. The progressive reduction in amplitude of postsynaptic potentials can be attributed solely to a lower probability of release, as shown by the fall of the binomial parameter $p$. 'T'his evidence supports the concept that $p$ is a critical variable for short-term modifications of synaptic efficacy and may provide insight for instances of synaptic plasticity underlying those behavioral changes which can be attributed to presynaptic loci. The present study also represents a necessary step toward linking mathematical variables of models for transmitter exocytosis with subcellular events.
\end{abstract}

In the case of the extensively studied gill withdrawal reflex of Aplysia, the decrease in intensity of a reflex response during habituation and, conversely, its facilitation are due to prolonged changes in synaptic strength achieved by regulating the amount of chemical transmitter released from synaptic terminals of specific neurons (Kandel and Schwartz, 1982). A simpler paradigm for altered synaptic transmission is the frcquency-dependent depression, where the postsynaptic response to a test stimulus is smaller than that evoked by one or more conditioning stimuli. Nevertheless, this depression, which occurs at the neuromuscular junction (Eccles et al., 1941; Lundberg and Quilisch, 1953) and at neuronal synapses of vertebrates (Curtis and Eccles, 1960; Kuno, 1964), has features in common with behavioral habituation and facilitation, as it also has a purely presynaptic origin (Otsuka et al., 1962; Thies, 1965). However, in both vertebrate and invertebrate systems, a question critical to the analysis of synaptic plasticity and to

\footnotetext{
${ }^{1}$ This work was supported by grants from DGRST and Institut National de la Santé et de la Recherche Médicale. We thank Mrs. J. Nicolet for technical and secretarial assistance and B. Franc for help in programming.

${ }^{2}$ To whom correspondence should be addressed.
}

models of exocytosis remains unresolved: do the mechanisms by which transmitter output is regulated operate on the number, $n$, of quantal units available for release or on the probability of release of the quanta, expressed by the parameter $p$ ?

We have studied frequency-dependent depression at the Mauthner (M) cell inhibitory synapses (Faber and Korn, 1982), a favorable preparation in which $(i)$ the major difficulties which previously limited quantal analysis of synaptic potentials in the CNS have been overcome (Korn et al., 1981, 1982), (ii) pharmacological manipulation of release is not required, and (iii) complications encountered in other systems, such as superimposed facilitatory process (ref. in Eccles, 1964) and variable failure of impulse propagation in the presynaptic axonal tree (Hatt and Smith, 1976) are not pertinent. Consequently, we have been able to demonstrate, earlier, that at identified synapses, each terminal bouton functions in an all-or-none manner since their total equals the binomial parameter $n$ (Korn et al., 1981, 1982). We report that when presynaptic neurons are stimulated at higher frequencies, but within their normal range of activation (Faber and Korn, 1978), the $n$ and the quantal size, $q$, remain constant. In contrast, the fall of mean quantal content, $m$, results solely from a decrease in the 
probability of release, $p$, which thus appears to be the modifiable presynaptic variable governing synaptic efficacy under physiological conditions. This finding clarifies data obtained at other junctions and opens the possibility for molecular models of exocytosis where the release probability may have a physical correlate.

\section{Methods and Results}

Experiments combining computational procedures with systematic reconstruction of dye-injected presynaptic neurons were performed on goldfish (Carassius auratus) anesthetized with MS-222. The experimental system for gathering the electrophysiological and morphological data is represented diagrammatically in Figure $1 A$. Recordings from the $\mathrm{M}$ cell soma were made with $\mathrm{KCl}$-filled microelectrodes in order to convert inhibitory postsynaptic potentials (IPSPs) into depolarizing responses, as illustrated in Figure $1, B$ and $C$, which shows the full-sized collateral IPSP (Fig. $1 B$ ) evoked by antidromic stimulation of the $\mathrm{M}$ axon at the level of the spinal cord and fluctuating unitary IPSPs (Fig. 1C) produced by direct stimulation of a single presynaptic neuron (PHP cell). In each preparation, one cell belong- ing to either the M cell's collateral network (Korn et al., 1978) or a class of commissural vestibular interneurons (Zottoli and Faber, 1980; Triller and Korn, 1981), was identified by the presence of a passive hyperpolarizing potential (Faber and Korn, 1978) and was also impaled with a microelectrode filled with horseradish peroxidase (HRP) for intracellular stimulation and dye injection. Techniques for serially reconstructing stained cells were the same as those used before (Korn et al., 1981; Triller and Korn, 1982a). The response fluctuations were analyzed with a program which was developed for a MINC computer and determined the best fitting binomial description of the histogram of the evoked responses, taking into consideration contributions of background noise. That is, the algorithm involved a free search for the optimal combination of $n, p$, and $q$. Extraction of these binomial parameters is a problem of constraint deconvolution requiring the definition of a goodness-of-fit criterion, which was chosen as the likelihood criterion. The theoretical formulation and the principles of this fluctuation analysis and the limitations of the parametric estimates have been described extensively (Korn et al., 1981, 1982). In addition, since the amplitudes of the
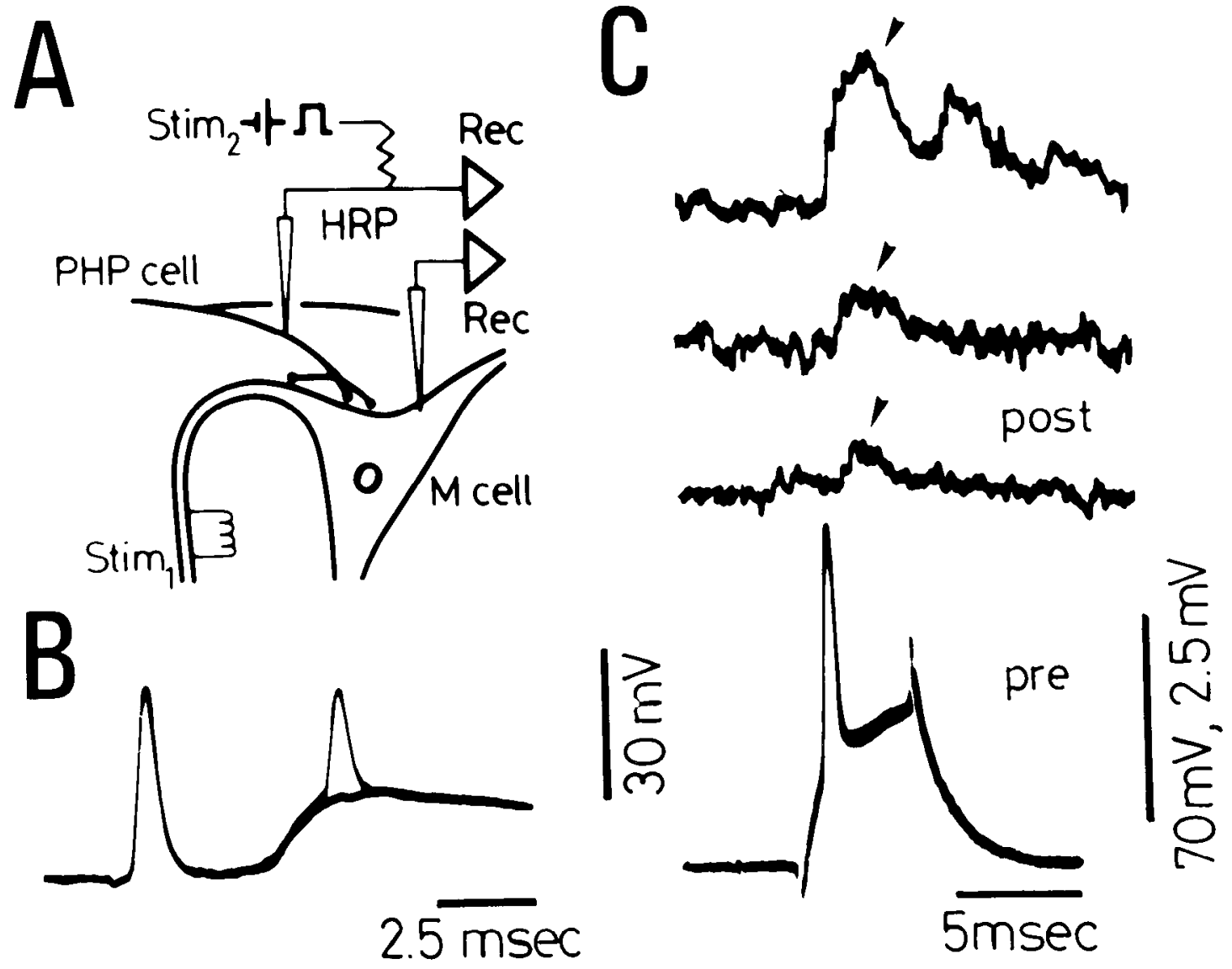

Figure 1. Fluctuating postsynaptic responses at an identified central synapse. $A$, Schematic representation of the experimental arrangement. Simultaneous intracellular recordings $(R e c)$ were obtained from the Mauthner cell $(M$ cell) and a presynaptic inhibitory interneuron (PHP cell), both cells being identified by their characteristic responses to antidromic stimulations (Stim $)_{1}$ of the $\mathrm{M}$ axon. The presynaptic electrode was also used for intracellular stimulation (Stim $)_{2}$ and subsequent iontophoretic injection of HRP. $B, \mathrm{M}$ cell antidromic spike followed by a collateral IPSP which is large enough to fire the cell in one of the two superimposed trials. $C$, The upper three traces illustrate amplitude variations of monosynaptic depolarizing unitary IPSPs (arrowheads) recorded in the $\mathrm{M}$ cell (post) following presynaptic spikes, induced at the rate of $2 \mathrm{~Hz}$, only one of which is shown in the lower trace (pre). 
fluctuating evoked responses were sometimes a significant fraction of the $\mathrm{Cl}^{-}$driving force, corrections for nonlinear summation of quantal components (Martin, 1955) were employed systematically: as described previously, the amplitude of the driving force is approximately twice that of the full-sized collateral IPSP (Faber and Korn, 1982).

Each of the 12 experiments analyzed here was conducted in the same manner. Because, in this system, depression is not observed at stimulation frequencies inferior to $3 \mathrm{~Hz}$ (Faber and Korn, 1982), presynaptic neurons were stimulated successively, as seen in Figure $2 A$, at the rates of $2,10,20$, and $33 \mathrm{~Hz}$ for sufficient time to generate sample sizes of 150 to 350 responses. Then, new trials were done at $2 \mathrm{~Hz}$, in order to check that the control responses had not changed in amplitude. This complete procedure was repeated at least twice before the presynaptic cell was stained. Special attention was given to the stability of the presynaptic spikes and to the stationarity (McLachlan, 1975) of the postsynaptic evoked potentials. First, since this depression reaches its maximum nearly instantaneously, the first five responses of each series were neglected, and a second, data recorded during the steady-state conditions were grouped into subsamples of 50 responses each, for a statistical analysis of their variance. Thus, in the experiments of Figures 1 and 2 , successive subsamples at $2 \mathrm{~Hz}$ averaged $1.06 \pm$ $0.24 \mathrm{mV}$ (mean $\pm \mathrm{SD}$ ), $0.99 \pm 0.24 \mathrm{mV}$, and $0.99 \pm 0.30$ $\mathrm{mV}$, while at $33 \mathrm{~Hz}$, the means were $0.64 \pm 0.26 \mathrm{mV}, 0.60$ $\pm 0.34 \mathrm{mV}, 0.62 \pm 0.26 \mathrm{mV}, 0.60 \pm 0.23 \mathrm{mV}, 0.65 \pm 0.27$ $\mathrm{mV}, 0.68 \pm 0.26 \mathrm{mV}$, and $0.60 \pm 0.23 \mathrm{mV}$, and no significant differences were found between the means of the groups $(p>10 \%)$.

Data illustrated in Figure 2, $B$ and $C$, are representa-

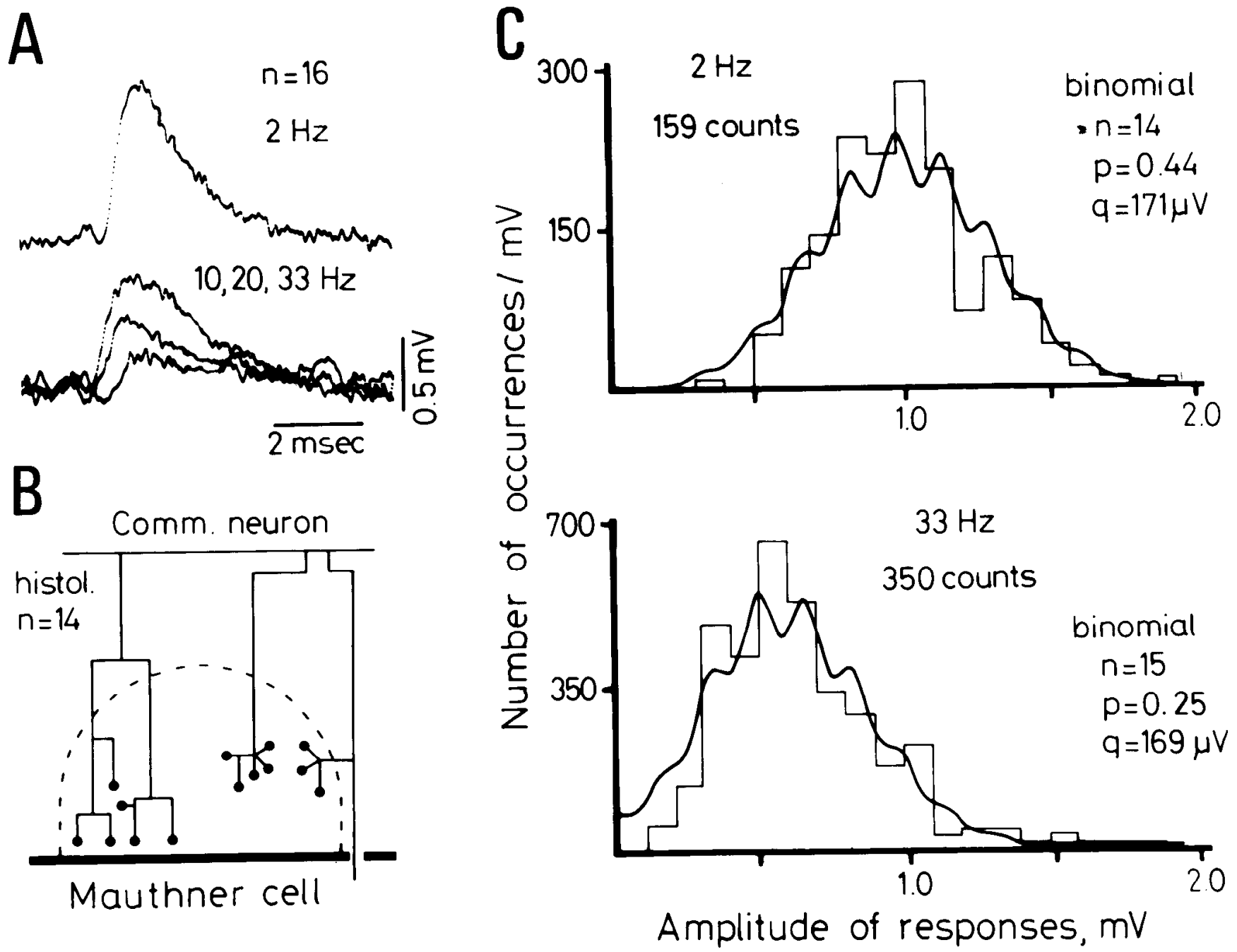

Figure 2. Binomial parameters $n, p$, and $q$ during synaptic depression (same experiment as in Fig. 1). A, Computer-averaged IPSPs $(n=16)$ recorded in the $M$ cell as the presynaptic inhibitory neuron was stimulated at different frequencies. Calculated on more than 150 counts, the mean amplitude of the evoked responses, which was about $1.01 \pm 0.27 \mathrm{mV}$ at the rate of $2 \mathrm{~Hz}$ (upper trace) fell progressively as the stimulus rate was increased to the indicated values (lower traces). B, Schematic representation of the reconstructed presynaptic cell's terminals. This commissural (Comm.) neuron established 14 synaptic boutons (solid circles) in relation with the $\mathrm{M}$ cell soma (thick line). $C$, Comparison of the probability density functions and best fits obtained with a binomial model, using 159 counts at $2 \mathrm{~Hz}$ (upper diagram) and 250 counts at $33 \mathrm{~Hz}$ (lower diagram). Note that synaptic depression was essentially associated with a lower probability of release, $p$, whereas $n$ and $q$ remained almost constant (Kolmogorov test satisfied with $p>0.09$ or above, and $p>0.05$ or below). 
live of the two major results obtained in this work, namely, that the decrease in the average postsynaptic response was associated with a decrease in $p$ and an unchanged $n$. In this case, a commissural neuron establishing 14 terminal boutons on the M cell soma or dendrites (Fig. 2B) was stimulated. For more than 150 sweeps in each case, the mean postsynaptic response, which was $1.01 \pm 0.27 \mathrm{mV}$ at $2 \mathrm{~Hz}$, fell to $0.80 \pm 0.29$ $\mathrm{mV}, 0.68 \pm 0.27 \mathrm{mV}$, and $0.63 \pm 0.28 \mathrm{mV}$ as the stimulus rate was increased to 10,20 , and $33 \mathrm{~Hz}$, respectively. The binomial statistics indicated that, for the lowest and highest frequencies $n$ changed a little, from 14 to 15 , respectively, while the release parameter $p$ was reduced from 0.44 to 0.25 , with the quantal size $q$ averaging 170 $\mu \mathrm{V}$ in both cases. Thus, all of the synaptic boutons remained functional under conditions of high frequency stimulation, and decreased transmitter output could be accounted for by a lower probability of release.

The observation that only $p$ is frequency dependent can be generalized to all of the experiments of the series, as shown by examples from another five of them, which are presented in 'Table 1 in order to emphasize the constancy of our findings, and as further indicated by the plots of normalized $n, p$, and $q$ in Figure 3 . The number of stained terminals ranged from 3 to 18 , and in each experiment the binomial $n$ of the best fit and the histological $n$ were essentially equivalent at all frequencies tested, as expressed by their mean ratio. Similarly, the quantal size $q$ remained remarkably stable and averaged $1.43 \pm 0.03 \%$ of the full collateral IPSP; that is, less than $1 \%$ of the driving force, as already observed earlier (Korn et al., 1982). This observation of a constant quantal size is in agreement with that of others (del
Castillo and Katz, 1954; Dudel and Kuffler, 1961; Kuno, 1964) and confirms the notion that apparent increases in $q$ rather reflect greater contributions of noise and measurement errors when postsynaptic potentials become smaller, or occasional shifts toward a Poisson representation when $p$ is drastically reduced (see Korn et al., 1982, Table I, for comparison of binomial and Poisson fits of the same data).

The mean values of $p$ were $0.56 \pm 0.14$ (range 0.75 to 0.33 ), $0.43 \pm 0.09$ (range 0.62 to 0.31 ), $0.33 \pm 0.09$ (range 0.46 to 0.21 ), and $0.25 \pm 0.05$ (range 0.35 to 0.19 ) at 2 , 10,20 , and $33 \mathrm{~Hz}$, respectively. Whether $p$ was normalized or expressed in absolute value, its frequency dependence fit an exponential curve with $p=p_{0}{ }^{e^{-k f}}+0.15$, although this relation was determined with a limited number of frequencies. Thus, there was a minimal probability around 0.15 , which is consistent with several experiments at higher frequencies where $p$ reached a plateau of about 0.12 .

\section{Discussion}

We previously reported (Korn et al., 1981, 1982) that there is a striking equivalence between the binomial term $n$ and the number of stained boutons, or more specifically, the number of presynaptic grids present in the terminals of the investigated neurons, since ultrastructural studies have shown that there is only one grid per bouton (Triller and Korn, 1982a). The stability of $n$ during depression is consistent with this identity and indicates that the underlying molecular mechanisms do not function to suppress individual boutons, but to regulate $p$ in a graded fashion. Although the Poisson model does not distinguish $n$ and $p$ as separate entities, but

TABLE I

Binomial parameters obtained in five experiments with different stimulus frequencies

Cells are listed in order of increasing $n$ 's. Unitary IPSP amplitude is expressed as mean \pm SD; note the agreement between these values and the products of the binomial parameters, $n, p$, and $q$. "Comm." and "Coll." indicate neurons that were part of the commissural and collateral networks, respectively.

\begin{tabular}{|c|c|c|c|c|c|c|c|c|}
\hline \multirow{2}{*}{ Exp. No. } & \multirow{2}{*}{ Cell Type } & \multirow{2}{*}{ Frequency } & \multirow{2}{*}{ Mean Unitary IPSP } & \multirow{2}{*}{$\begin{array}{c}\text { Histol. } \\
n\end{array}$} & \multicolumn{3}{|c|}{ Binomial Parameters } & \multirow{2}{*}{ Xo. of Counts } \\
\hline & & & & & $n$ & $p$ & $q(\mathrm{mV})$ & \\
\hline \multirow{5}{*}{82} & \multirow{5}{*}{ Comm. } & $\mathrm{Hz}$ & $m V$ & & & & & \\
\hline & & 2 & $1.02 \pm 0.28$ & 4 & 4 & 0.62 & 0.415 & 161 \\
\hline & & 10 & $0.78 \pm 0.27$ & 4 & 1 & 0.49 & 0.404 & 214 \\
\hline & & 20 & $0.73 \pm 0.30$ & 4 & 4 & 0.45 & 0.406 & 331 \\
\hline & & 33 & $0.57 \pm 0.28$ & 4 & 4 & 0.35 & 0.404 & 350 \\
\hline \multirow[t]{4}{*}{83} & \multirow[t]{4}{*}{ Comm. } & 2 & $1.68 \pm 0.29$ & 6 & 6 & 0.70 & 0.410 & 162 \\
\hline & & 10 & $1.09 \pm 0.27$ & 6 & 6 & 0.45 & 0.412 & 236 \\
\hline & & 20 & $0.70 \pm 0.41$ & 6 & 5 & 0.35 & 0.410 & 319 \\
\hline & & 33 & $0.48 \pm 0.32$ & 6 & 6 & 0.20 & 0.406 & 350 \\
\hline \multirow[t]{4}{*}{80} & \multirow[t]{4}{*}{ Comm. } & 2 & $1.23 \pm 0.30$ & 7 & 7 & 0.53 & 0.340 & 150 \\
\hline & & 10 & $0.98 \pm 0.33$ & 7 & 7 & 0.42 & 0.340 & 183 \\
\hline & & 20 & $0.73 \pm 0.30$ & 7 & 6 & 0.36 & 0.350 & 240 \\
\hline & & 33 & $0.70 \pm 0.34$ & 7 & 7 & 0.29 & 0.340 & 187 \\
\hline \multirow[t]{4}{*}{76} & \multirow[t]{4}{*}{ Comm. } & 2 & $1.99 \pm 0.37$ & 12 & 12 & 0.74 & 0.234 & 169 \\
\hline & & 10 & $0.92 \pm 0.32$ & 12 & 13 & 0.35 & 0.218 & 259 \\
\hline & & 20 & $0.67 \pm 0.37$ & 12 & 12 & 0.21 & 0.268 & 238 \\
\hline & & 33 & $0.65 \pm 0.38$ & 12 & 13 & 0.19 & 0.257 & 293 \\
\hline \multirow[t]{4}{*}{71} & \multirow[t]{4}{*}{ Coll. } & 2 & $2.76 \pm 0.58$ & $16 / 17$ & 17 & 0.54 & 0.310 & 95 \\
\hline & & 10 & $1.60 \pm 0.57$ & $16 / 17$ & 17 & 0.31 & 0.305 & 163 \\
\hline & & 20 & $1.14 \pm 0.64$ & $16 / 17$ & 17 & 0.22 & 0.310 & 185 \\
\hline & & 33 & $1.01 \pm 0.67$ & $16 / 17$ & 17 & 0.19 & 0.315 & 290 \\
\hline
\end{tabular}



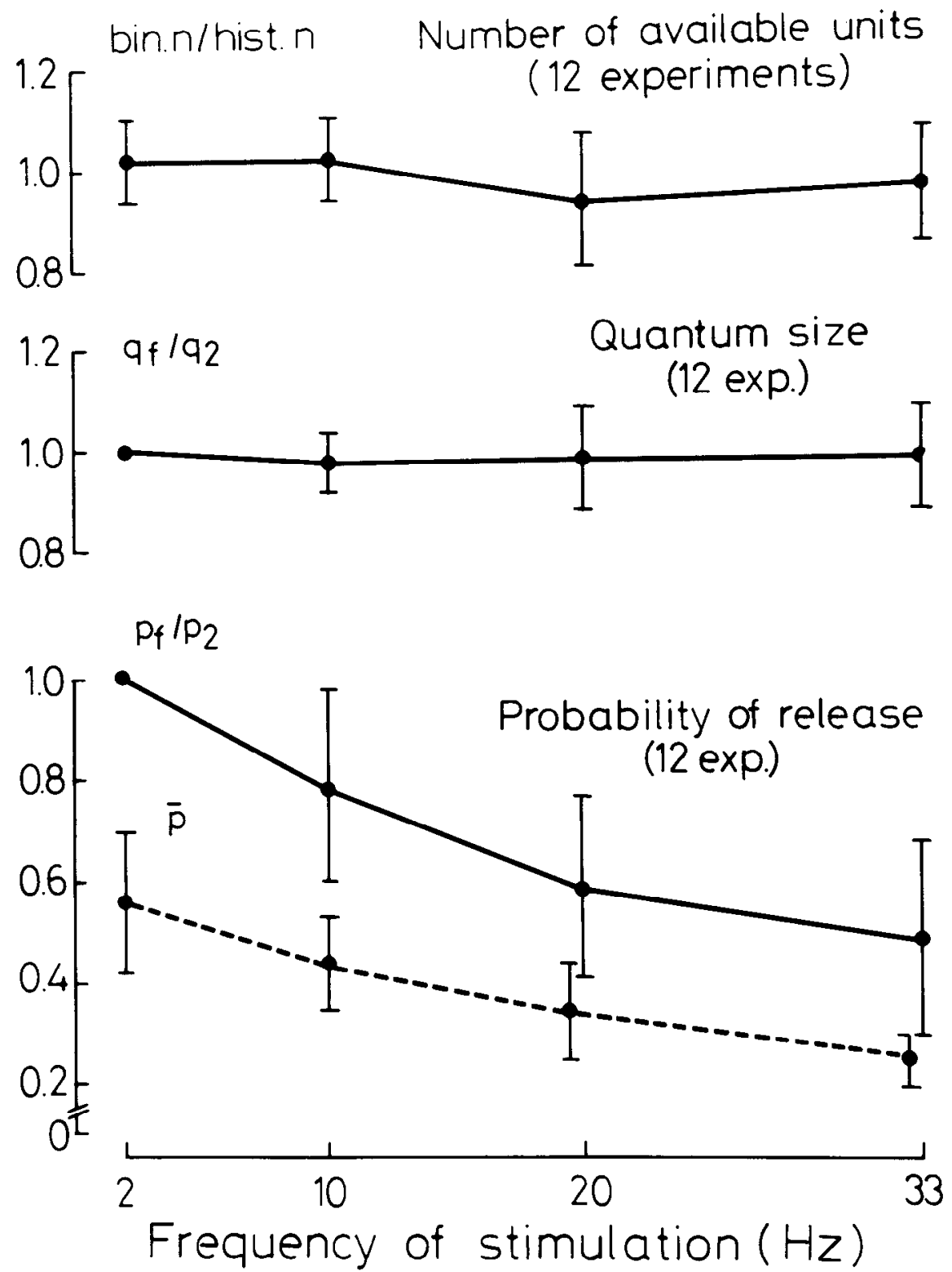

Figure 3. Relative changes in the statistics of transmitter release during depression, as observed in 12 experiments. Upper diagram, Plot of the mean normalized number of units available for release, represented by the ratio bin $n_{f} /$ hist. $n$, which is the ratio between the computer-estimated $n$ at each of the indicated frequencies and the histologically determined number of synaptic boutons. Middle diagram, Plot of the mean normalized quantum size, represented by $q_{f} / q_{2}$; i.e., by the ratio between the size of the quanta at each frequency and its control value at $2 \mathrm{~Hz}$. Lower diagrams, Mean probability of release, normalized to its control value $\left(p_{f} / p_{2}\right.$, solid line) or represented in absolute value $(\bar{p}$, dashed line). Vertical bars indicate standard deviations of the means.

rather provides a value for the $n p$ product or mean quantal content, previous investigators did use it to conclude indirectly that $p$ is reduced during depression (del Castillo and Katz, 1954; Dudel and Kuffler, 1961; Kuno, 1964) by assuming that $n$ remains constant when $n p$ drops. Binomial analysis of the reduction in $m$ by low calcium also indicated that $p$ alone varied (Wernig, 1972). Although other reports seem to be in contradiction with our finding, it should be pointed out that a decrease of $n$ alone at the developing neuromuscular junction (Bennett and Florin, 1974) is not necessarily indicative about events at mature synapses. Also, decreases of both $p$ and $n$ (Betz, 1970; Christensen and Martin, 1970; McLachlan, 1975) or of $n$ alone (Bennett et al., 1976) were due to depletion produced by prolonged stimulations in rather nonphysiological conditions ( $p$ then falling as the size of the available quanta is reduced; McLachlan, 1975). Finally, the increase in $n$ preceding that of $p$ during facilitation (Bennett et al., 1976) supports our conclusion since it was interpreted as indicating that more active sites became active, their maximum corresponding, as in our preparation, to the number of the nerve's terminal 
varicosities. Thus, the conclusions drawn from the $\mathbf{M}$ cell model can indeed be generalized to other systems in which short-term changes in synaptic efficacy are also due to the regulation of transmitter release.

The mechanism for reducing $p$ could be accomplished in a number of ways. For example, it could be due to an active calcium-dependent process sensitive primarily to $\mathrm{Ca}^{2+}$ influx, rather than to $\left[\mathrm{Ca}^{2+}\right]_{i}$, which presumably increases during repetitive stimulation. Certainly, this concept is consistent with observations that fatigue disappears once transmission is depressed by lowering $\left[\mathrm{Ca}^{2+}\right]_{0}$ (Takeuchi, 1958; Thies, 1965; Taschiro et al., 1976). In view of our results indicating that, at the $M$ cell's inhibitory synapses, at most, one vesicle is released following each presynaptic impulse (Korn et al., 1981, 1982 ), it is possible that a decrease in $p$ reflects a transient refractoriness of the release sites (Betz, 1970), or, in other words, partial recovery of a release mechanism which had been temporarily blocked by the preceding exocytotic event, particularly since there appears to be a deformation of the presynaptic grid after exocytosis (Triller and Korn, $1982 \mathrm{a}$, b).

\section{References}

Bennett, M. R., and T. Florin (1974) A statistical analysis of the release of acetylcholine at newly formed synapses in striated muscle. J. Physiol. (Lond.) 238: 93-107.

Bennett, M. R., T. Florin, and A. G. Pettigrew (1976) The effect of calcium ions on the binomial statistic parameters that control acetylcholine release at preganglionic nerve terminals. J. Physiol. (Lond.) 257: 597-620.

Betz, W. J. (1970) Depression of transmitter release at the neuromuscular junction. J. Physiol. (Lond.) 206: 629-644.

Christensen, B. N., and A. R. Martin (1970) Estimates of probability of transmitter release at the mammalian neuromuscular junction. J. Physiol. (Lond.) 210: 933-945.

Curtis, D. R., and J. C. Eccles (1960) Synaptic action during and after repetitive stimulation. J. Physiol. (Lond.) 150:374398.

del Castillo, J., and B. Katz (1954) Statistical factors involved in neuromuscular facilitation and depression. J. Physiol. (Lond.) 124: 574-585.

Dudel, J., and S. W. Kuffler (1961) Mechanism of facilitation at the crayfish neuromuscular junction. J. Physiol. (Lond.) 155: 530-542.

Eccles, J. C. (1964) The Physiology of Synapses, SpringerVerlag, Berlin.

Eccles, J. C., B. Katz, and S. W. Kuffler (1941) Nature of the "endplate" potential in curarized muscle. J. Neurophysiol. 5: 362-387.

Faber, D. S., and H. Korn (1978) Electrophysiology of the Mauthner cell: Basic properties, synaptic mechanisms and associated networks. In Neurobiology of the Mauthner Cell, D. S. Faber and H. Korn, eds., pp. 47-131, Raven Press. New York.

Faber, D. S., and H. Korn (1982) Transmission at a central inhibitory synapse. I. Magnitude of unitary postsynaptic conductance change and kinetics of channel activation. J.
Neurophysiol. 48: 654-678.

Hatt, H., and D. O. Smith (1976) Synaptic depression related to presynaptic conduction block. J. Physiol. (Lond.) 259: 367-393.

Kandel, E. R., and J. H. Schwartz (1982) Molecular biology of learning: Modulation of transmitter release. Science 218: $433-443$.

Korn, H., A. Triller, and D. S. Faber (1978) Structural correlates of recurrent collateral interneurons producing both electrical and chemical inhibitions of the Mauthner cell. Proc. R. Soc. Lond. (Biol.) 202: 533-538.

Korn, H., A. Triller, A. Mallet, and D. S. Faber (1981) Fluctuating responses at a central synapse: $n$ of binomial fit predicts number of stained presynaptic boutons. Science 213 : 898-901.

Korn, H., A. Mallet, A. Triller, and D. S. Faber (1982) Transmission at a central inhibitory synapse. II. Quantal description of release, with a physical correlate for binomial $n$. J. Neurophysiol. 48: 679-707.

Kuno, M. (1964) Mechanism of facilitation and depression of the excitatory synaptic potential in spinal motoncurons. J. Physiol. (Lond.) 175: 100-112.

Lundberg, A., and H. Quilisch (1953) Presynaptic potentiation and depression of neuro-muscular transmission in frog and rat. Acta Physiol. Scand. Suppl. 111: 111-120.

Martin, A. R. (1955) A further study of the statistical composition of the end-plate potential. J. Physiol. (Lond.) 130:114122.

McLachlan, E. M. (1975) Changes in statistical release parameters during prolonged stimulation of preganglionic nerve terminals. J. Physiol. (Lond.) 253: 477-491.

Otsuka, M., M. Endo, and Y. Nonomura (1962) Presynaptic nature of neuromuscular depression. Jpn. J. Physiol. 12: 573583.

Takeuchi, A. (1958) The long-lasting depression in neuromuscular transmission of frog. Jpn. J. Physiol. 8: 102-113.

Taschiro, N., J. P. Gallagher, and S. Nishi (1976) Facilitation and depression of synaptic transmission in amphibian sympathetic ganglia. Brain Res. 118: 45-62.

Thies, R. E. (1965) Neuromuscular depression and the apparent depletion of transmitter in mammalian muscle. J. Neurophysiol. 28: $427-442$.

Triller, A., and H. Korn (1981) Morphologically distinct classes of inhibitory synapses arise from the same neurons: Ultrastructural identification from crossed vestibular interneurons intracellularly stained with HRP. J. Comp. Neurol. 203: 131155.

Triller, A., and H. Korn (1982a) Transmission at a central inhibitory synapse. III. Ultrastructure of physiologically identified and stained terminals. J. Neurophysiol. 48: 708736.

Triller, A., and H. Korn (1982b) Déformations de la grille présynaptique liées l'exocytose dans les synapses centrales. C.R. Acad. Sci. Paris Ser. III 295: 655-660.

Wernig, A. (1972) Changes in statistical parameters during facilitation at the crayfish neuromuscular junction. J. Physiol. (Lond.) 226: 751-759.

Zottoli, S. J., and D. S. Faber (1980) An identifiable class of statoacoustic interneurons with bilateral projections in the goldfish medulla. Neuroscience 5: 1287-1302. 